\title{
Students' Experiences in EDIC+ Intensive Programmes
}

\author{
Ghazala Bhatti
}

Theorising and exploring the meaning of empowerment, social justice, citizenship and democracy in academic papers is one thing. Teaching about it in order to make future teachers and administrators consider policy and practice and facilitate their participation in research is another. The EDIC+ project tried to do both, when Masters and doctoral students came together from seven universities and they worked with academics from their own and other universities. We thought it would be useful to capture student voices and to see what they made of what we were trying to do, and what we could do better next time. Was there something we should do differently, and if so what and how? This teaching and learning experience sought to make students confident learners who could express their views and explore different perspectives in a space which was not their usual place of learning. In addition to other positive experiences, it was hoped that as a consequence of their participation on the EDIC project they would be able to think more critically about their own research projects.

Elspeth Jones (2010) discusses the value in students and their tutors working in ways which underline the importance of international experiences. The idea of the global citizen who is well-informed and capable is a very attractive one. In their research with Erasmus students Golubeva et al. (2018) capture students' views about 'active citizenship'. They report that students' understanding agreed with the definition of the concepts provided in the research literature. The EDIC project made it possible to try two developmental ideas which would feed into the final module. One was IP (Intensive Programme lasting ten days) and the other was a 'try-out' module held once or twice at each university between 2016 and 2019.

Students from seven universities met and studied together for ten days at the Intensive Programmes held between 4th and 14th June 2017 at Charles University, Prague. Then from 14th to 24th May 2018 when 23 students from seven universities met for ten days at the Universities of Tallinn and Helsinki. The final Intensive Programme meeting was held at Aristotle University, Thessaloniki between 13th and 23rd March 2019. 
We obtained ethical clearance from Bath Spa University ethics committee to gather data from participating students. The research with students attending IP on EDIC was optional. There were no strict parameters set on any concepts the students might use, and no predefined outcomes. The questions students were invited to respond to were very open ended. These were:

1. What were 2 things (enjoyable and different) to what I'm used to?

2. What I found challenging and why?

3. What did I learn from my peers?

4. What did I contribute?

5. What did I learn about myself as a student/researcher?

Data was collected mainly through students learning diaries which they were invited to submit to one researcher within one or two weeks of completing the Intensive Programme and in the case of three 'pilot' or 'try out' modules, immediately after completing those modules. The students could structure their answers as they wished. They could use sub headings or illustrations or photographs - anything they wished. They were assured that their identities would not be shared with anyone except the one researcher, nor the full data sets which would identify them and their tutors or their universities. In addition to this, 15 students from one university were prepared to take part in 3 separate focus group discussions, as well as provide data collected through follow-on individual in-depth ethnographic interviews.

When introducing the idea of research and seeking informed consent from the students one of the key readings used in the IP in Charles University Prague was Morwenna Griffith's (2003) essay on empowerment. Other students in subsequent IPs were also informed of this text which would explain why their voices were important and how their ideas would be shared. That a ten day Intensive Programme would help this process of 'empowerment' (whatever that means!) was initially met with ambiguity, puzzlement and a vague sort of interest. That this was not a normal 'evaluation of the module' puzzled some students. That it was important to record their views and what they wrote would be taken seriously was made clear to all who took part. After the end of the Intensive Programme or the end of the try out module when students submitted their learning diaries they acknowledged that they had been to quote one student 'on a big journey of change'.

Data was coded and sub categories emerged from the written and spoken (and recorded) texts. What is set out below is based on a selection of what the students said and wrote down to share on two IPs and three try out modules. This is anonymised data from 25 students from a total of 56 students who were invited to take part at different points during the three year duration of the EDIC project. 
Overall, students greatly appreciated the opportunity to meet other post graduate students from their own and other universities. Even students from the same university did not sometimes have the opportunity of working closely with their own peers inside their own university until they attended the IP.

\subsection{International Encounters}

The most poignant texts are those which capture what the students shared about their interactions with students from other countries. If these participants become teachers or they train teachers one day, then these shared moments will probably help them to be better informed educators. It is a notable feature of European Universities that they attract post graduate students from across the world, who travel to Europe to study for Masters and doctoral degrees. The nationalities represented during the first two IPs and some tryout modules included students from the seven universities in Finland, Greece Spain, Tallinn, The Czech Republic, The Netherlands, UK, plus students from Columbia, China, Ghana, Iran, Pakistan, Somalia, Switzerland, Syria, Venezuela and Zambia. These are some of the students' words:

It sounds bad but all I knew about Iran was what the media told me. Some stupid backward things. On TV I see these men and women in black cloaks protesting against the west ...! It was amazing and so wonderful to learn something else, more relevant, more honest, more human from someone who knew so much more about my country than I knew about Iran. I would like to visit Iran. (Interview)

By the time we got to the end of that talk about what was happening in Venezuela (in 2018) to young people, to children, there was not a single dry eye in the room. What an artificial protected world I have lived in all my life. (Interview)

Ghana was somewhere in Africa. A dot on the map. But we saw a film about Asanti university and me and my other friends from universities in Europe sat up. What a great campus it was and what an absolutely inspirational guy is leading it! That night when we got talking we thought there has to be a EDIC project set up in Ghana. I think we told her that we will go and help her (the student from Ghana). (Journal notes) 
China is huge. Before this IP I had not realized what was actually happening in their schools. I have learnt there is so much going on and I know so little about it in the mainland, in Hong Kong. All I know is a bit about my own country's educational policies. (Journal notes)

\subsection{Working in English Language}

Fluent speakers of the English language forget that they must remember some students need a little more time to respond quickly. The speed at which words are spoken was mentioned more than once.

I did not feel confident with speaking quickly in English. Same with some other students from other places. But that was only for the first two days. Third day I stopped speaking in my own language to my friends from my university. I wanted to learn about Greece, about China and not just be with my own university friends always, and I didn't care about my English. (Journal notes)

People who speak fast in English including teachers, sometimes leave us behind. But it is not possible to interrupt. That is the main problem I had sometimes. (Journal notes)

I was appalled I was the only one in class who could only speak English ... Never experienced that before among so many people. I mean even the tutors spoke Dutch, or Spanish or Greek or Finnish ... (Interview)

I was shocked to learn people were talking in English as their third or fourth language. It is frightening how little I know! How few languages I was taught at school. (Interview)

\subsection{Excursions and Off-Campus Visits}

It was really appreciated that students met other people besides their normal teachers and tutors. They found it very educational and useful. It was the element of surprise together with the learning that was commented upon.

Meeting Igor Blazevic in that Laika café was like something out of a nineteenth century novel. We read novels about revolution. We don't meet such people in real life, only in films. This was so unexpected, so humbling. I know this changed me somehow - the way he talked about his work, his passion for his country, his idealism. I have never met anyone 
international like that. Thank you to Dana! [Tutor responsible for organizing Prague programme]. (Journal notes)

We stood in the ruins and we wrote poetry in the 'tough Czech north'. It was a strange experience walking through the ruins of the homes the Germans left behind. This was so memorable for me personally including how badly people were treated who worked in the mines. I feel I must read more history. We do not have such places in the Netherlands. (Journal notes)

It was an eventful afternoon strolling the streets of Tallinn's Old City with the high school students who were very knowledgeable about their history and incredible legends. I had never even heard of Tallinn before. (Journal notes)

\subsection{On Learning Together}

The excitement of learning together was shared by more than half of the students. They felt outside their comfort zone but then got used to 'all of us going everywhere together all the time' as one of them noted.

It is not until you are thrown together that you really learn from each other. I am normally not very extrovert, and pushy. I normally follow on. But as the IP was in my country, there I was talking and talking about where to go, what to see! Then in class I could share things easily next day. I have made friends for life. I can't believe it. (Interview)

It is such a gift to have an opportunity to really learn together, to be made to think hard and to be honest with each other about what you learn. I feel very privileged. Very fortunate that I was selected to be on this programme. (Journal notes)

I have learnt that each and every one of my peers has taught me something new and important. This can be about themselves, or their value system, or their hopes for the future, or their hopes for education in their country. Some were shy at the very beginning, but not at the end. (Journal notes)

Since I left high school and I went on school trips, I can't remember going on a trip with so many people all together! Hard working trip but also such a very fun trip. In school we were all from same neighbourhood, 
same country. This is so much more exciting, so amazing, so educational. Sometimes we don't want to go to sleep- there is so much to talk about. (Journal notes)

\section{$1.5 \quad$ On Teachers}

Although direct information was not sought about teachers, about a third of the students commented on those who taught them.

We should meet these teachers once a year, every year. I have learnt SO much from the 14 teachers who tutored us and were patient with us. It is sad we will not meet them again. (Journal notes)

Each lecturer was so different from the others. Each speaker was adding and adding to our knowledge and understanding about the subject they were so passionate about ... Just by being themselves they were also teaching us how to teach, how to be with students and the real value of EDIC. (Journal notes)

This IP was a great learning experience, touching areas that many find sensitive or too subjective to address. And the honesty of the professors was exemplary. They opened the space up for us to engage with each other without being judged. (Journal notes)

We don't know how to thank our teachers, so we will not be able to do that. Ever. (Journal notes)

These are just some of the views students shared. There were not many negative points. Most students felt fortunate to be part of the project.

Discussion

Overall, it is fair to say that this was a productive and valuable learning experience for most student participants. They appreciated the opportunity to work intensively together for ten whole days. Two students managed to attend two IPs and found their own additional funding to attend the second IP because they had enjoyed the first IP so much and because they had learnt so much. For at least one Masters student, attending the first IP led to writing a $\mathrm{PhD}$ proposal which helped him obtain a fully funded scholarship for three years. For some the experience of IP and of EDIC was in their own words 'transformational'. 
For others it was challenging and to quote two students 'boundary pushing' and 'totally outside my comfort zone'. For another student it was 'beyond my expectations.' No one regretted participating in the Intensive Programmes and no one wanted to leave when it was over. This might indicate that only those students had applied to go on EDIC Intensive Programmes who were willing to take risks and be challenged in the first place. For all teachers it was a great opportunity to network and plan and look forward to the next opportunity of collaborative work, which was academic, educational, social and fulfilling.

\section{References}

Golubeva, I., Parra, E., \& Mohedano, R. (2018). What does 'active citizenship' mean for Erasmus students? Intercultural Education, 20(1), 40-58.

Jones, E. (2010). Internationalization and the student voice: Higher education perspective. London: Routledge. 